\title{
In Vitro Characterization of Pluronic F127 and D- $\alpha$-Tocopheryl Polyethylene Glycol 1000 Succinate Mixed Micelles as Nanocarriers for Targeted Anticancer-Drug Delivery
}

\author{
Adeel Masood Butt, ${ }^{1}$ Mohd Cairul Iqbal Mohd Amin, ${ }^{1}$ Haliza Katas, ${ }^{1}$ Narong Sarisuta, ${ }^{2}$ \\ Wasu Witoonsaridsilp, ${ }^{2}$ and Ruthairat Benjakul ${ }^{2}$ \\ ${ }^{1}$ Centre for Drug Delivery Research, Faculty of Pharmacy, Universiti Kebangsaan Malaysia, Jalan Raja Muda Abdul Aziz, \\ 50300 Kuala Lumpur, Malaysia \\ ${ }^{2}$ Department of Manufacturing Pharmacy, Faculty of Pharmacy, Mahidol University, 447 Sri-Ayudhya Road, \\ Bangkok 10400, Thailand
}

Correspondence should be addressed to Mohd Cairul Iqbal Mohd Amin, mciamin@yahoo.co.uk

Received 7 April 2012; Revised 6 July 2012; Accepted 31 July 2012

Academic Editor: Jun Liu

Copyright (C) 2012 Adeel Masood Butt et al. This is an open access article distributed under the Creative Commons Attribution License, which permits unrestricted use, distribution, and reproduction in any medium, provided the original work is properly cited.

Mixed micelles of Pluronic F127 and D- $\alpha$-tocopheryl polyethylene glycol 1000 succinate (TPGS) in different molar ratios (10:0, $7: 3,5: 5$, and $3: 7$ ) were prepared to characterize this system as nanocarriers for targeted delivery of chemotherapeutic agents. Their size, zeta potential, critical micelle concentration, drug loading content, entrapment efficiency, drug release, cytotoxicity, and stability in serum were evaluated in vitro by using doxorubicin as the model anticancer drug. The micellar sizes ranged from 25 to $35 \mathrm{~nm}$. The $7: 3$ and 5:5 micellar combinations had lower critical micelle concentrations $\left(5 \times 10^{-5} \mathrm{M}\right)$ than the $10: 0$ combination $\left(5 \times 10^{-4} \mathrm{M}\right)$. The entrapment efficiencies of the $7: 3,5: 5$, and $3: 7$ micellar combinations were $72 \%, 88 \%$, and $69 \%$, respectively. Doxorubicin release was greater at acidic tumour $\mathrm{pH}$ than at normal physiological $\mathrm{pH}$. The doxorubicin-loaded mixed micelles showed greater percent inhibition and apoptosis activity in human breast adenocarcinoma (MCF-7) and acute monocytic leukaemia (THP-1) cell lines than free doxorubicin did. The mixed micelles were also stable against aggregation and precipitation in serum. These findings suggest that Pluronic F127-TPGS mixed micelles could be used as nanocarriers for targeted anticancerdrug delivery.

\section{Introduction}

Chemotherapy, radiotherapy, surgery, monoclonal antibody strategies, and complementary alternative therapy [1] are a few approaches for managing various types of cancer. Among these, chemotherapy is the major and most successful therapeutic approach for both localized and metastasized cancers [2]. However, its application is limited by the lack of selectivity, severe toxicity [3], and continuous development of resistance to chemotherapeutic agents over time. Resistance develops due to the overexpression of P-glycoproteins, which function as drug efflux pumps; these glycoproteins lower the efficacy of chemotherapeutic agents by pumping the drugs from cells. Besides, most anticancer drugs are highly hydrophobic and thus poorly soluble in aqueous solutions, which hinder their clinical administration. Low efficacy of chemotherapeutic agents is also attributable to their poor penetration and limited distribution in solid tumours [4]. The use of drug delivery systems such as drug-polymer conjugates and adjuvants and techniques such as drug encapsulation and solubilization can overcome these problems. The use of nanocarriers such as: nanoparticles [5, 6], liposomes $[7,8]$, nanospheres [9-11], and polymeric micelles [12-15] is another strategy for increasing the efficacy of chemotherapeutic drugs. These strategies are aimed at delivering drugs selectively into tumour cells and increasing their permeability across the cells.

Polymeric micelles occur spontaneously due to the aggregation of amphiphilic molecules in which the hydrophobic moieties form the micellar core and the hydrophilic ends 
form the structural shell. The micellar diameter typically ranges from 10 to $1000 \mathrm{~nm}$. Because of their small size, micelles are capable of delivering drugs into poorly permeable tumours such as solid tumours by their enhanced permeability and retention (EPR) effects [12]. Some successful micellar nanocarriers have been studied in different phases of clinical trials [16-19]. Numerous natural and synthetic polymers have been successfully employed for the development of polymeric micelles, including polyethylene glycol, poly(aspartic acid), poly(lactide-co-glycolide), and Pluronic block copolymers. Among these, Pluronic block copolymers are highly interesting due to their nonionic and nontoxic nature, flexibility for use in different pharmaceutical formulations, and good selectivity against cells with MDR [20].

Pluronics are the block copolymers of poly(ethylene oxide) and poly(propylene oxide). Their ability to prolong the circulating time of drugs has attracted research in their use as drug delivery systems for various types of drugs [21]. Pluronic block copolymers could sensitize cells with MDR by inhibiting P-glycoproteins through selective energy depletion [22]. Moreover, Pluronic micelles enhance pro-apoptotic signalling, thereby sensitizing tumour cells; these cells are therefore more vulnerable to the effects of anticancer drugs [23]. For example, potentiation of cytotoxicity is observed when doxorubicin is administered in combination with Pluronic [24].

Despite these advantages, Pluronic micelles have poor stability and low drug entrapment efficiency. Mixed micelles are widely used to address these problems $[19,25,26]$. D$\alpha$-tocopheryl polyethylene glycol 1000 succinate (TPGS), a water-soluble form of vitamin $\mathrm{E}$, is employed as a component of mixed micellar systems to improve their stability and the absorption of certain drugs. TPGS also facilitates drug uptake by tumour cells and selective cytotoxicity by inducing apoptosis via the production of reactive oxygen species (ROS) [27].

The objective of this study was to characterize Pluronic F127-TPGS (Figure 1) mixed micelles as nanocarriers for targeted delivery of chemotherapeutic agents. Their size, zeta potential, critical micelle concentration, drug loading content (DLC), entrapment efficiency (EE), drug release, cytotoxicity, and stability in serum were evaluated in vitro by using doxorubicin as the model anticancer drug.

\section{Materials and Methods}

2.1. Materials. Pluronic F127, foetal bovine serum (FBS), and Hoechst 33342 were purchased from Sigma-Aldrich (St. Louis, MO, USA). TPGS and dimethyl sulphoxide (DMSO) were supplied by Sigma-Aldrich Chemie GmbH (Steinheim, Germany). Doxorubicin hydrochloride and 4-(2-hydroxyethyl)piperazine-1-ethanesulphonic acid (HEPES)-buffered saline (HBS) were purchased from EMD Biosciences (Calbiochem, San Diego, CA, USA). Triethylamine, dichloromethane, and chloroform were purchased from Merck Schuchardt OHG (Hohenbrunn, Germany). Trypsin-ethylenediaminetetraacetic acid (EDTA) and 3-(4,5-dimethylthiazol-2-yl)-2,5-diphenyltetrazolium bromide (MTT) were supplied by Life Technologies (Invitrogen Molecular Probes, Eugene, OR, USA). Roswell Park Memorial Institute medium (RPMI-1640) and Dulbecco's modified Eagle's medium (DMEM) were also purchased from Life Technologies (Gibco, Carlsbad, CA, USA).

\subsection{Preparation of Doxorubicin-Loaded Mixed Micelles.} Pluronic F127 and TPGS in different molar ratios $(10: 0,7: 3$, $5: 5$, and $3: 7$ ) were dissolved in $10 \mathrm{~mL}$ of chloroform to obtain a series of solutions. Thin films produced from these solutions by solvent evaporation were freeze-dried under vacuum. The freeze-dried films were then rehydrated with $10 \mathrm{~mL}$ of $5 \mathrm{mM} \mathrm{HBS}$ and incubated at $37^{\circ} \mathrm{C}$ for $30 \mathrm{~min}$ to obtain a micellar suspension. This suspension was filtered through a $0.22-\mu \mathrm{m}$ nylon filter (Whatman; GE Healthcare Life Sciences, Piscataway, NJ, USA) to obtain mixed micelles of uniform size.

To obtain doxorubicin-loaded mixed micelles, the freezedried films and $2.5 \mathrm{mg}$ doxorubicin hydrochloride were dissolved in a mixture of $5 \mathrm{~mL}$ dichloromethane and $50 \mu \mathrm{L}$ triethylamine. The mixture was added dropwise to $50 \mathrm{~mL}$ deionized water and sonicated for $5 \mathrm{~min}$. Dichloromethane and triethylamine were then evaporated and the remaining solution was subjected to ultrafiltration in a stirred cell (molecular weight cut-off [MWCO] 1000; EMD Millipore, Billerica, MA, USA) to eliminate nonloaded doxorubicin. The resulting concentrate was then freeze-dried to obtain a dark red powder of doxorubicin-loaded mixed micelles.

2.3. Analysis of Size and Zeta Potential. Hydrodynamic radii and zeta potentials of the mixed micelles were determined by dynamic light scattering (DLS) method (Zetasizer Nano ZS; Malvern Instruments, Worcestershire, UK) at $37^{\circ} \mathrm{C}$.

2.4. Morphological Analysis. Samples for morphological analysis were prepared by air-drying a drop of micellar suspension on a carbon-coated formvar film on a 400 mesh copper grid. The micellar morphology was then visualized by transmission electron microscopy (TEM; Tecnai Spirit, FEI, China) at $220 \mathrm{kV}$ and under different magnifications.

2.5. Determination of Critical Micelle Concentration (CMC). The critical micelle concentrations (CMCs) of the mixed micelles were determined by the dynamic light-scattering (DLS) method (Zetasizer Nano ZS, Malvern Instruments) at $37^{\circ} \mathrm{C}$ and a scattering angle of $90^{\circ}$. The changes in light intensity were recorded, and a graph was plotted between the molar concentration of the samples and the mean intensity. A sharp increase in the intensity indicated the formation of micelles.

2.6. Determination of Drug Loading Content and Entrapment Efficiency. The amount of doxorubicin loaded into the mixed micelles was determined from the calibration curve of pure doxorubicin. Freeze-dried doxorubicin-loaded mixed micelles were dissolved in $5 \mathrm{~mL}$ DMSO, and the absorbance was measured at $482 \mathrm{~nm}$ by using a UV-1601 spectrophotometer (Shimadzu Corp., Kyoto, Japan) [28]. Drug loading 


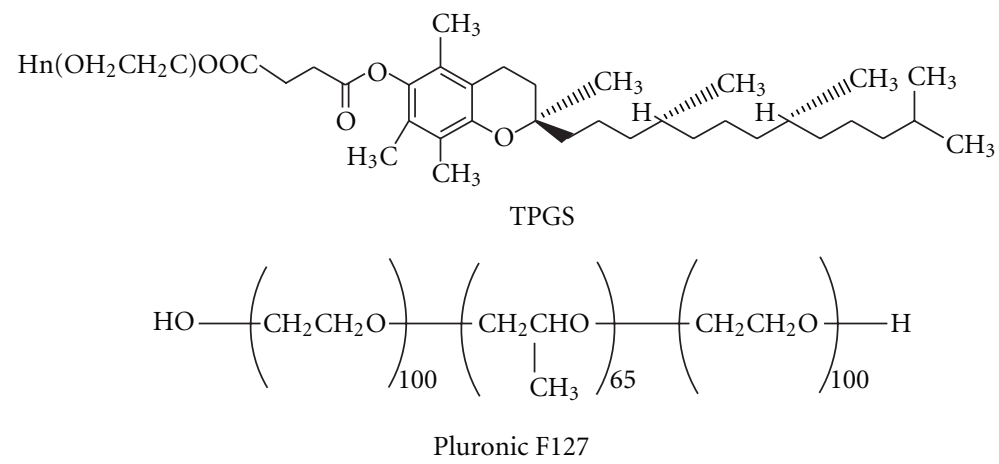

Figure 1: Chemical structures of Pluronic F127 and D- $\alpha$-Tocopheryl POLYEThYLENE GLYCol 1000 suCCINATE (TPGS).

content (DLC) can be defined as the ratio of mass of the drug encapsulated within the micelles to the total mass of drug loaded micelles. Whereas entrapment efficiency (EE) is the ratio of mass of drug loaded into the micelles to the mass of drug initially added. The drug loading content and entrapment efficiency were then calculated according to the following equations:

Drug loading content (wt $\%)$

$$
=\frac{\text { mass of drug encapsulated in micelles }}{\text { mass of drug-loaded micelles }} \times 100,
$$

Entrapment efficiency (\%)

$$
=\frac{\text { mass of drug loaded in micelles }}{\text { mass of drug initially added }} \times 100 \text {. }
$$

2.7. Attenuated Total Reflectance Fourier Transform Infrared Spectroscopy. The ATR-FTIR spectra of free doxorubicin, doxorubicin-loaded mixed micelles, and blank mixed micelles were recorded against the background by using a universal ATR sampling assembly (Spectrum 100; PerkinElmer, Waltham, MA, USA). For each sample, 16 scans were obtained at a resolution of $4 \mathrm{~cm}^{-1}$ in the range of 4000 to $400 \mathrm{~cm}^{-1}$.

2.8. Drug Release Study. Doxorubicin release from the mixed micelles was analyzed at $\mathrm{pH} 7.4$ and 5 to simulate the in vivo physiological and tumour $\mathrm{pH}$, respectively. A known amount of doxorubicin-loaded mixed micelles was dispersed in $4 \mathrm{~mL}$ phosphate-buffered saline (PBS). Then, $2 \mathrm{~mL}$ of doxorubicin-loaded mixed micelles was placed into a dialysis bag (MWCO 10000, Sigma-Aldrich). After both ends were sealed, the bag was immersed in $50 \mathrm{~mL}$ of PBS (pH 5 or 7). The whole sample was maintained at $37^{\circ} \mathrm{C}$ and shaken at $100 \mathrm{rpm}$. At the appropriate intervals, $3-\mathrm{mL}$ samples were collected from the release medium and an equal volume of fresh medium was added to the release medium. The concentration of doxorubicin in each sample was measured by ultraviolet-visible spectrophotometry at $482 \mathrm{~nm}$.

2.9. Stability Study. The stability of the mixed micelles was assessed by the DLS method and transmittance measure ments in the presence of DMEM supplemented with $10 \%$ FBS. Blank and doxorubicin-loaded mixed micelles were incubated in DMEM with $10 \%$ FBS for $72 \mathrm{~h}$ at $37^{\circ} \mathrm{C}$ while being shaken at $100 \mathrm{rpm}$. The average micellar size $(d)$ and transmittance $(T)$ were determined at specified intervals. The ratios of $d_{i}$ to $d_{0}$ and $T_{i}$ to $T_{0}(\%)$, where " $i$ " and " 0 " represent a particular interval and the baseline, respectively, were calculated and plotted against time.

2.10. Cell Culture. Human breast adenocarcinoma (MCF-7), human acute monocytic leukaemia (THP-1), and Chinese hamster lung fibroblast (V79) cell lines were obtained from American Type Culture Collection (ATCC, Manassas, VA, USA). THP-1 cells were cultured and maintained in a suspension culture in RPMI-1640 medium supplemented with $10 \%$ FBS and $1 \%$ penicillin-streptomycin. MCF-7 and V79 cells were cultured in DMEM supplemented with $10 \% \mathrm{FBS}$ and $1 \%$ penicillin-streptomycin. All cultures were maintained at $37^{\circ} \mathrm{C}$ in a humidified $5 \% \mathrm{CO}_{2}-95 \%$ air atmosphere.

2.11. Cytotoxicity Analysis. The effect of the blank micelles on cell viability was assessed by using V79 cells. Cultured cells maintained in DMEM were seeded in 96-well culture plates at $5 \times 10^{4}$ cells per well and incubated for $24 \mathrm{~h}$. They were then treated with increasing concentrations of blank mixed micelles ranging from 10 to $1000 \mu \mathrm{g} \mathrm{mL} L^{-1}$ and incubated for another $24 \mathrm{~h}$ at $37^{\circ} \mathrm{C}$ in $5 \% \mathrm{CO}_{2}$ atmosphere. Subsequently, $20 \mu \mathrm{L}$ of Alamar Blue was added to each well and incubation was continued for $4 \mathrm{~h}$. The absorbance of each sample at $570 \mathrm{~nm}\left(A_{570}\right)$ was measured with a microplate reader (Varioskan Flash; Thermo Scientific, Waltham, MA, USA). Cell viability was determined by using the following equation:

$$
\text { Cell viability }(\%)=\frac{A_{570} \text { of treated cells }}{A_{570} \text { of control cells }} \times 100 \text {. }
$$

The cytotoxicity of the doxorubicin-loaded mixed micelles was determined by the MTT colorimetric assay. MCF-7 and THP-1 cells were seeded in 96-well culture plates at $2 \times 10^{4}$ and $2 \times 10^{5}$ cells per well, respectively, and incubated for $48 \mathrm{~h}$ at $37^{\circ} \mathrm{C}$ in $5 \% \mathrm{CO}_{2}$ atmosphere. After the medium was removed, MCF-7 cells were treated with $200 \mu \mathrm{L}$ of $12.5,6.25,3.13,1.56$, and $0.78 \mu \mathrm{g} \mathrm{mL}^{-1}$ concentrations and 
THP- 1 cells were treated with $200 \mu \mathrm{L}$ of $2.0,1.0,0.5,0.25$, and $0.12 \mu \mathrm{g} \mathrm{mL}^{-1}$ concentrations of free doxorubicin and doxorubicin-loaded mixed micelles. After $24 \mathrm{~h}$ of incubation, $50 \mu \mathrm{L}$ MTT solution was added to each well and incubation was continued for $4 \mathrm{~h}$. Isopropanol was then added to each well to dissolve the formazan crystals formed from the reduction of MTT by mitochondria of living cells. The absorbance of each sample at $570 \mathrm{~nm}$ was measured by using a microplate reader (Infinite M200; Tecan, Männedorf, Switzerland). The percent inhibition was calculated from the cell viability by using the following equation:

$$
\text { Percent inhibition }(\%)=100-\text { cell viability. }
$$

2.12. Apoptosis Assay. MCF-7 and THP-1 cells were seeded in 96-well culture plates at $5 \times 10^{3}$ and $5 \times 10^{4}$ cells per well in DMEM and RPMI-1640 medium, respectively. The cells were incubated for at least $48 \mathrm{~h}$. They were then treated with free doxorubicin, and doxorubicin-loaded mixed micelles in various ratios for another $24 \mathrm{~h}$. Thereafter, $5 \mu \mathrm{g} \mathrm{mL}^{-1}$ of Hoechst 33342 (nuclear specific dye) was added to each well and the plates were incubated for $10 \mathrm{~min}$ in the dark at $37^{\circ} \mathrm{C}$. The plates were visualized under a fluorescence microscope (FluoView confocal microscope; Olympus, Center Valley, PA, USA) by using bright field and 4',6-diamidino-2phenylindole (DAPI) filters. Each cell producing bright blue fluorescence was marked and counted as an apoptotic cell (i.e., showing pyknotic nuclei or karyorrhexis).

2.13. Statistical Analysis. All experiments were performed in triplicate. The data represent mean standard deviation (SD) or standard error of mean (SEM). The significance of the results was tested by using a one-way analysis of variance followed by post hoc Dunnett's multiple-comparison test. A $P$-value of less than 0.05 was considered significant.

\section{Results and Discussion}

3.1. Size, Zeta Potential, and Morphology. The micellar size actually represents the hydrodynamic radius of the particles in Brownian motion. The size and zeta potential of the Pluronic F127-TPGS mixed micelles determined from DLS measurements are shown in Table 1. The micellar size in the $10: 0$ combination was $22 \pm 2.02 \mathrm{~nm}$, and the mixed micelles were slightly larger than the single polymer. A gradual increase in micellar size was observed in the $7: 3$ and 5:5 combinations, which could be explained by the entrapment of TPGS hydrophobic parts with poly(propylene oxide) in the micellar core. However, in the 3:7 combination, the micellar size reduced; this slight reduction could be attributed to the presence of a greater amount of TPGS polymers, which may enhance the interaction between the hydrophobic chains and the components of both polymeric mixtures, thus resulting in a more compact structure. Such nanosized micelles can accumulate in pathological tissues due to their EPR effects, which enables drug delivery into permeable tumours [25].
TEM micrographs of blank and doxorubicin-loaded mixed micelles are shown in Figure 2. Their typical core-shell architecture is shown in the inset of Figure 2(a). The micelles were spherical in shape and uniform in size. The bright areas (inset) possibly comprised hydrophobic poly(propylene oxide) and TPGS segments forming the micellar core whereas the hydrophilic corona appeared to be darker because it has higher electron density compared to core. This finding is in agreement with Tan et al. (2012) [29]. The micellar size determined by TEM was similar to that determined by the DLS method.

3.2. Critical Micelle Concentration. The CMCs of a series of Pluronic F127-TPGS solutions in different molar ratios are shown in Figure 2(c). Changes in the light intensity are represented as a function of the molar concentration in which a sudden increase in intensity indicates the formation of stable micelles. The CMC of the $7: 3$ and $5: 5$ combinations was $5 \times 10^{-5} \mathrm{M}$ and that of the $10: 0$ and $3: 7$ combination was $5 \times 10^{-4} \mathrm{M}$. These findings are in agreement with previous reports $[15,21]$. The results show that the mixed micelles in the $7: 3$ and 5:5 ratios had lower critical micelle concentrations than the pure polymer (10:0 ratio). Therefore, mixed micelles are more stable than pure polymeric micelles. This could again be explained by the presence of TPGS polymers, which could increase the hydrophobic interactions between the polymeric chains in the micellar core and stabilize the structure [26]. In addition, the high number of poly(propylene oxide) moieties could provide a synergistic effect with the hydrophobic part of TPGS and this combination could improve the stability of the mixed micelles and ensure the formation of a larger micellar core. Both processes are important for the drug solubilization and entrapment efficiency of mixed micelles $[9,30]$. However, the Pluronic F127-TPGS mixed micelles were more stable only up to a certain concentration of TPGS (i.e., in the $7: 3$ and $5: 5$ combinations). When the molar fraction of TPGS was increased further, it increased hydrophilic segments which elevated the probability of interaction between hydrophilic and hydrophobic segments and a reduced hydrophobicity of the core subsequently leading to an increased CMC. High CMCs are a major problem related to micellar formulations given intravenously or diluted in blood. Low CMCs of Pluronic F127-TPGS mixed micelles would therefore offer some advantages such as stability against dissociation and precipitation in blood due to dilution. Moreover, embolism caused by the high amount of polymers used for micelle formation could be avoided [31].

3.3. Drug Loading Content and Entrapment Efficiency. The drug loading content and entrapment efficiency of different samples are shown in Table 1. The results indicate that doxo-rubicin was successfully incorporated into the mixed micelles. The improved entrapment efficiency of the $7: 3$ and $5: 5$ combinations could be a result of the increased micellar core size due to the increased hydrophobic interactions within the core by the presence of the TPGS polymers and poly(propylene oxide) moieties. This also resulted in 
TAble 1: Characterization of mixed micelles. The critical micelle concentration (CMC), size, zeta potential, drug loading content, and entrapment efficiency of mixed micelles. Data is represented as mean $\pm \operatorname{SD}(n=3),{ }^{\mathrm{a}}={ }^{*} P<0.05,{ }^{\mathrm{b}}={ }^{* *} P<0.01$ compared to $10: 0$ combination.

\begin{tabular}{lccccc}
\hline Sample & CMC $(\mathrm{M})$ & Size $(\mathrm{nm})$ & Zeta potential $(\mathrm{mV})$ & DLC $(\%)$ & $1.5 \pm 0.06$ \\
\hline $10: 0$ & $5 \times 10^{-4}$ & $22 \pm 2.02$ & $-10 \pm 0.58$ & $2.1 \pm 0.23^{\mathrm{b}}$ & $72 \pm 7.5^{\mathrm{a}}$ \\
$7: 3$ & $5 \times 10^{-5}$ & $26 \pm 1.32$ & $-10 \pm 0.94$ & $-13 \pm 1.50$ & $2.8 \pm 0.14^{\mathrm{b}}$ \\
$5: 5$ & $5 \times 10^{-5}$ & $35 \pm 2.81^{\mathrm{b}}$ & $-15 \pm 1.99^{\mathrm{b}}$ & $4.1 \pm 0.13^{\mathrm{b}}$ & $88 \pm 7.4^{\mathrm{b}}$ \\
$3: 7$ & $5 \times 10^{-4}$ & $28 \pm 1.20^{\mathrm{a}}$ & $69 \pm 4.6^{\mathrm{a}}$ \\
\hline
\end{tabular}

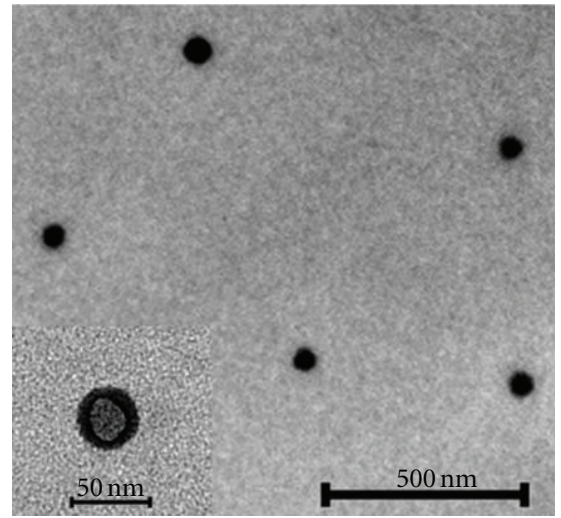

(a)

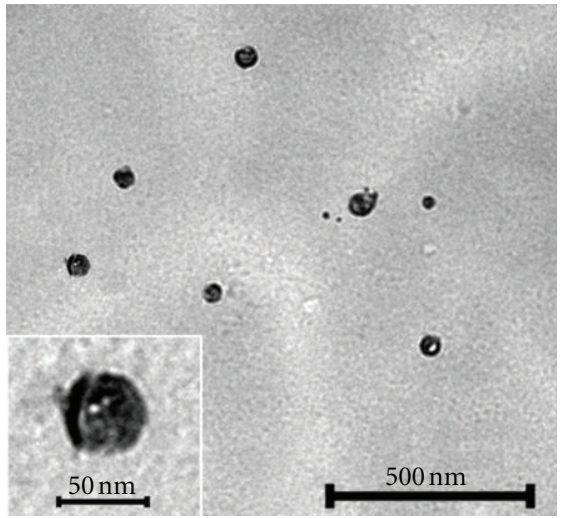

(b)

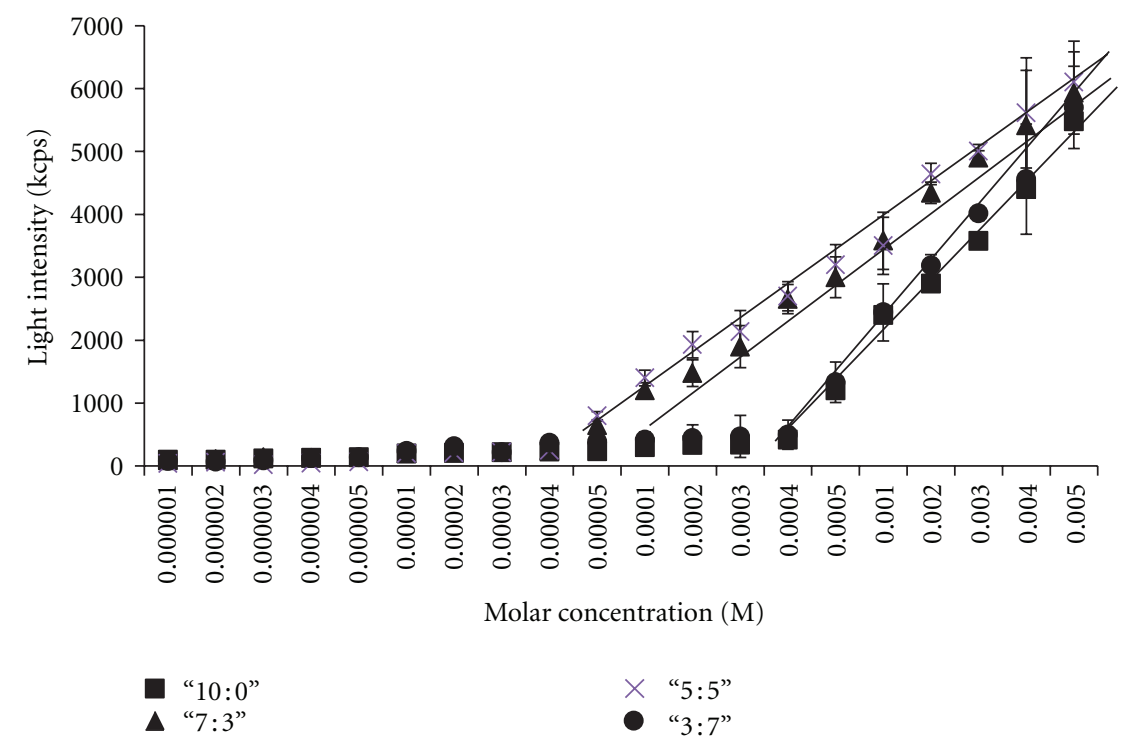

(c)

FIGURE 2: Characterization of mixed micelles. TEM images of mixed micelles: (a) blank mixed micelles $(7: 3)$; inset is a single micelle showing typical core-shell architecture of micelles, (b) doxorubicin-loaded mixed micelles; inset is a single doxorubicin loaded mixed micelle, (c) CMC of mixed micelles determined using DLS method by plotting the concentration against light intensity; each point represents average \pm $\mathrm{SD}(n=3)$.

improved partitioning of hydrophobic doxorubicin in the micellar core. Moreover, the reduced entrapment efficiency of the $3: 7$ combination could be explained by the decreased core size.

Doxorubicin localization in the micellar core was detected via the ultraviolet-visible spectra of pure doxorubicin and doxorubicin entrapped in the micelles, as shown in Figure 3(a). The maximum absorption of doxorubicin shifted from 482 to $502 \mathrm{~nm}$. This shift towards a longer wavelength (i.e., the red shift observed for doxorubicin-loaded micelles) could be due to $\pi-\pi$ stacking and may indicate that doxorubicin was localized within the micellar core [32]. 


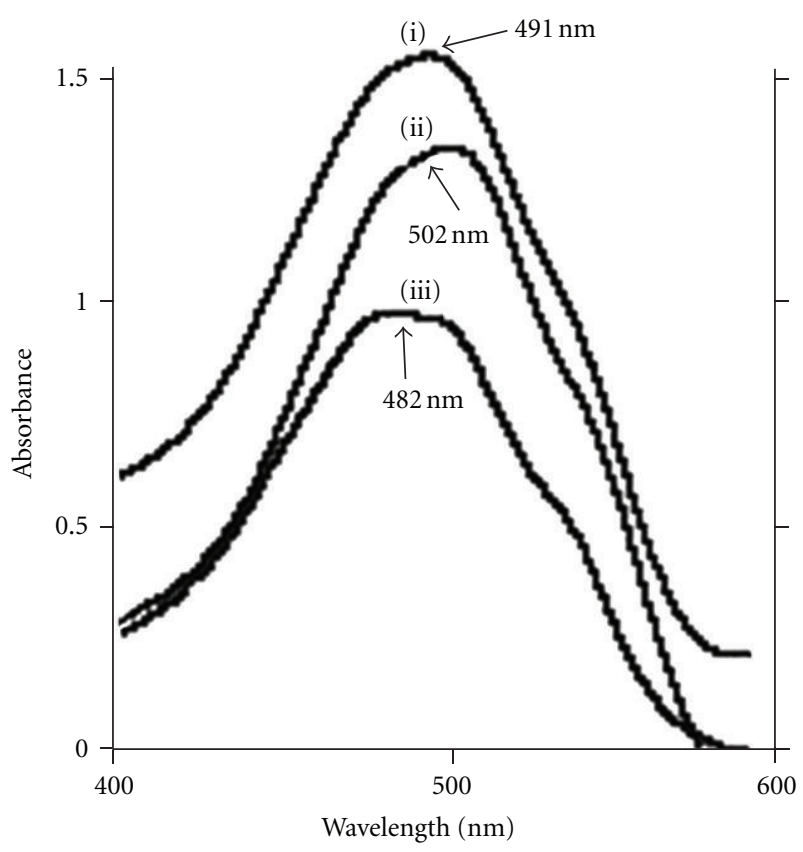

(a)

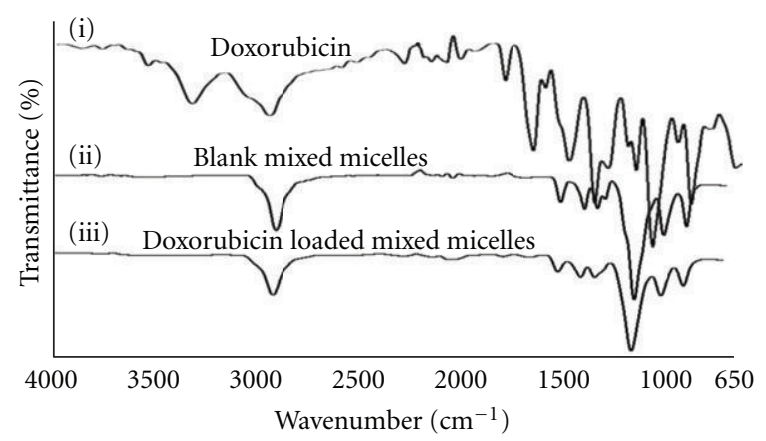

(b)

FIGURE 3: Spectroscopic analysis of blank mixed micelles, doxorubicin, and doxorubicin loaded mixed micelles. (a) ultraviolet visible spectra of (i) doxorubicin released from micelles in release medium, (ii) doxorubicin loaded into mixed micelles, and (iii) free doxorubicin, (b) FTIR-ATR spectra (i) pure doxorubicin, (ii) blank mixed micelles, and (iii) doxorubicin-loaded mixed micelles.

However, the red shift is insignificant when considering the stability of doxorubicin, as discussed in Section 3.4.

The ATR-FTIR spectra of doxorubicin-loaded mixed micelles were compared with those of blank mixed micelles and free doxorubicin, as shown in Figure 3(b). The spectra of the doxorubicin-loaded mixed micelles showed the absence of characteristic peaks for doxorubicin, suggesting that the drug was localized and entrapped within the hydrophobic micellar core [33].

3.4. Drug Release. The percent cumulative drug release is shown in Figure 4. Doxorubicin release from the micelles occurred in 2 phases: a phase of burst release followed by a phase of slow and gradual release. These phases were affected by the $\mathrm{pH}$ of the release medium. Less and slower release of

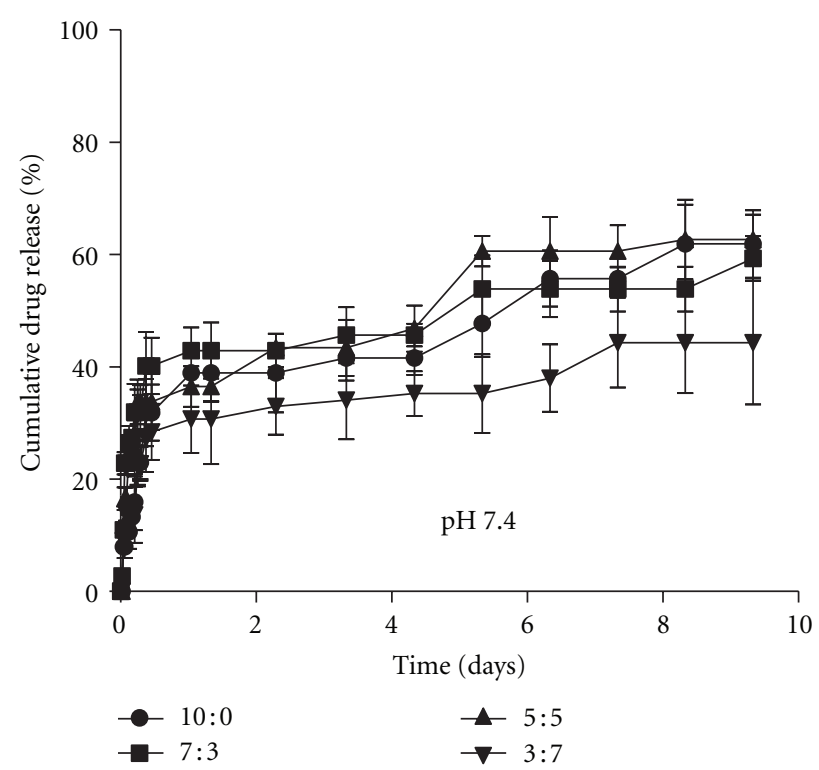

(a)

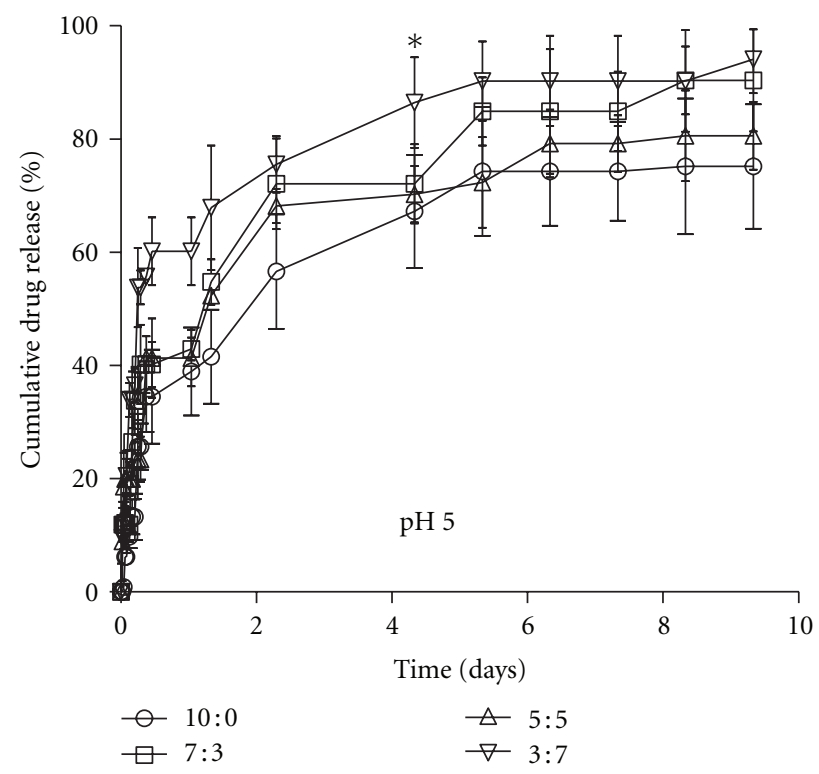

(b)

Figure 4: Drug release at $37^{\circ} \mathrm{C}(\mathrm{pH} 5$ and 7$)$. The $\%$ cumulative doxorubicin released from micelles in $\mathrm{PBS}$ at $\mathrm{pH} 5$ and 7.4 at $37^{\circ} \mathrm{C}$, each point represents average $\pm \mathrm{SD}(n=3),{ }^{*} P<0.05$.

doxorubicin was observed at $\mathrm{pH} 7.4$ than at $\mathrm{pH}$ 5. Moreover, the burst release occurred in the first $8 \mathrm{~h}$ at both $\mathrm{pH} 7.4$ and $\mathrm{pH}$ 5. This was followed by a small release of the drug at $\mathrm{pH} 7.4$; the maximum cumulative drug release $(\sim 60 \%)$ occurred after $9 \mathrm{~d}$. However, at $\mathrm{pH} 5$, the cumulative drug release reached up to $90 \%$ in the same period. The burst release of doxorubicin from the mixed micelles may be a result of rapid disruption of the micellar system due to cohesion, higher concentration gradient, and sink conditions in the system. This release could achieve the therapeutic concentration and the gradual increase could maintain 
the concentration. The burst release from the $3: 7$ combination accounted for $40 \%$ and $60 \%$ of the cumulative drug release at $\mathrm{pH} 5$ and 7.4, respectively, which could be attributed to the higher critical micelle concentration of this combination. The 7:3 and 5:5 combinations released comparatively lesser doxorubicin at the same time, which could be explained by their lower critical micelle concentration and greater stability. The doxorubicin release from the $7: 3$ combination at pH 5 after $4 \mathrm{~d}$ was significantly higher $(P<0.05)$ than that from the 10:0 combination. Further, about $40-45 \%$ of the drug was released from the mixed micelles in $4 \mathrm{~d}$ at $\mathrm{pH} 7.4$ compared with the $75-85 \%$ released in the same period at $\mathrm{pH}$ 5. The amount of doxorubicin release after the first $4 \mathrm{~d}$ could be attributed to the reduced stability of the micelles. The lower drug release at $\mathrm{pH} 7.4$ could be beneficial because slow and sustained release of doxorubicin from micelles at physiological $\mathrm{pH}$ could reduce the adverse effects associated with nonspecific uptake of doxorubicin. The increased drug release at $\mathrm{pH} 5$ could be explained by the higher partition coefficient of doxorubicin in the acidic medium compared with that in the micellar core. However, doxorubicin-loaded mixed micelles could have increased therapeutic efficacy because of their increased mean residence time in tumours through EPR effects and enhanced drug release in the tumour environment.

The ability of mixed micelles to protect and deliver a drug to the target site is an important aspect of drug delivery. The ability of a micelle to protect a drug can be investigated by evaluating the drug's structure. Evaluation of the stability of doxorubicin in the release medium was carried out by comparing the ultraviolet-visible spectra of pure doxorubicin and doxorubicin from the mixed micelles. In the case of structural alterations, positional changes of functional groups, or complete breakdown of a compound, the ultraviolet-visible spectrum will change. Free doxorubicin showed the maximum absorption peak at $482 \mathrm{~nm}$ and that of doxorubicin released from the mixed micelles was $491 \mathrm{~nm}$, as shown in Figure 3(a). The spectrum showed no signs of deterioration, indicating that the mixed micelles could protect the released drug.

3.5. Stability. Micelles can become disrupted by the presence of serum proteins [34]. Their stability in the presence of serum proteins is thus vital, because serum contains numerous proteins, which may affect the micellar stability and reduce their efficiency. The physical stability of doxorubicinloaded mixed micelles was investigated in the presence of DMEM supplemented with 10\% FBS. Doxorubicin forms aggregates and precipitates in the presence of FBS due to the interaction with serum proteins.

As shown in Figure 5 , the $T_{i}: T_{0}$ ratio of free doxorubicin decreased by up to about $50 \%$, indicating the presence of aggregates and precipitation. In contrast, an increase in transmittance was observed for the doxorubicin-loaded mixed micelles in the presence of FBS. This increase could be attributed to the formation and precipitation of drugdrug aggregates, drug-protein aggregates, or protein-protein aggregates. In general, micelles bound to serum proteins are

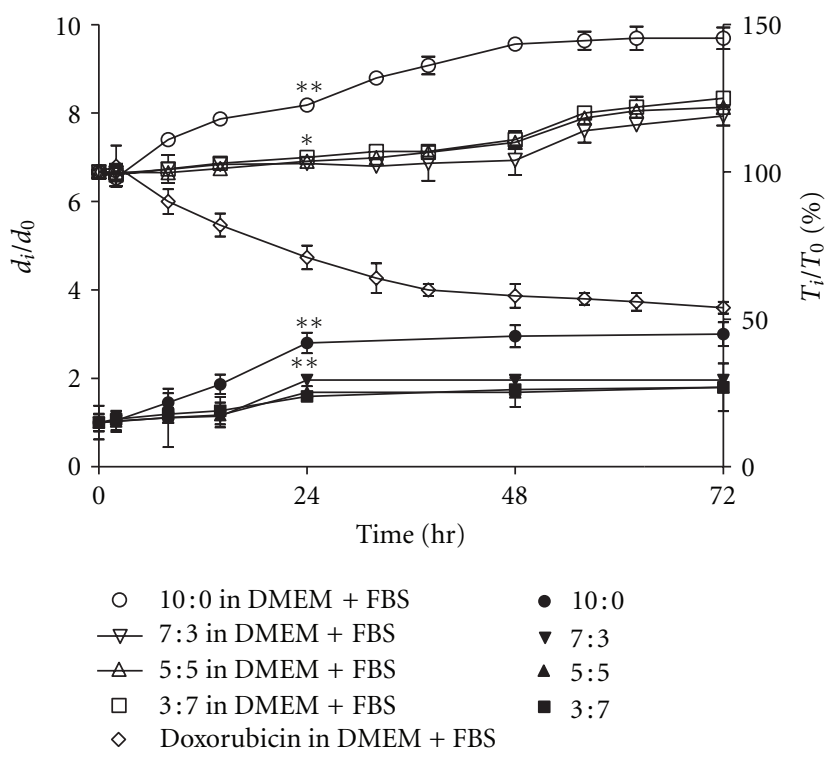

FIGURE 5: Stability of mixed micelles in FBS and DMEM. Transmittance and diameter of mixed micelles are represented as $T_{i} / T_{0}$ (\%) (right $y$-axis) and $d_{i} / d_{0}$ (left $y$-axis). $10 \%$ of FBS was used for all the stability studies, each point represents mean $\pm \mathrm{SD}(n=3)$, ${ }^{*} P<0.05,{ }^{*} P<0.01$ compared to $10: 0$ combination.

larger in size than unbound micelles. As shown in Figure 5, a significant $(P<0.01)$ increase in micellar size $\left(d_{i}: d_{0}\right.$ ratio $)$ was observed in the first $24 \mathrm{~h}$, whereas no significant change was observed from 48 to $72 \mathrm{~h}$ of incubation. The increased size in the first $24 \mathrm{~h}$ indicates an interaction between the micelles and the serum proteins. Concurrently, an increase in transmittance was observed, indicating precipitation of larger sized aggregates. The 10:0 combination showed faster precipitation than the other 3 combinations. The increased stability of the mixed micelles could be attributed to the presence of TPGS in the mixture, which could enhance colloidal stability of the system [35]. Moreover, the poly(ethylene oxide) segment of Pluronic could have reduced the formation of aggregates with serum proteins, rendering stability and preventing precipitation due to the presence of oxygen atoms.

3.6. Cytotoxicity. As shown in Figure 6, the percent inhibition increased from the $10: 0$ to the $3: 7$ combinations. Pluronic F127-TPGS mixed micelles augmented doxorubicin cytotoxicity in cancer cells although the polymers, that is, Pluronic F127 and TPGS, did not affect normal cells indicating their safety.

To confirm the low toxicity of mixed micelles to normal cells, cell viability was determined in V79 cells. The blank mixed micelles were not toxic to V79 cells in the analyzed concentration ranges (Figure $7(\mathrm{a})$ ).

However, the doxorubicin-loaded mixed micelles induced cell death in both MCF-7 and THP- 1 cells (Table 2 and Figure 6). The half-maximal inhibitory concentration $\left(\mathrm{IC}_{50}\right.$ ) values for the doxorubicin-loaded mixed micelles were lower 
TABLE 2: The mean \% inhibition and average $\mathrm{IC}_{50}(\mu \mathrm{M})$ of doxorubicin-loaded mixed micelles in MCF-7 and THP- 1 cells. \% inhibitions for equal concentrations of doxorubicin-loaded micelles are shown for a selected concentration only, data represented as mean \pm SEM $(n=3)$, $\mathrm{b}={ }^{* *} P<0.01$ compared to free doxorubicin.

\begin{tabular}{lcccc}
\hline \multirow{2}{*}{ Sample } & \multicolumn{2}{c}{ Mean inhibition $(\%)$} & \multicolumn{2}{c}{ Average IC50 $(\mu \mathrm{M})$} \\
& MCF-7 & THP-1 & MCF-7 & \\
\hline $10: 0$ & $81.88 \pm 0.72^{\mathrm{b}}$ & $76.17 \pm 2.78^{\mathrm{b}}$ & $9.64 \pm 0.31^{\mathrm{b}}$ & \\
$7: 3$ & $82.93 \pm 1.77^{\mathrm{b}}$ & $80.59 \pm 8.17^{\mathrm{b}}$ & $6.27 \pm 0.08^{\mathrm{b}}$ & $0.16 \pm 0.03^{\mathrm{b}}$ \\
$5: 5$ & $86.77 \pm 2.90^{\mathrm{b}}$ & $83.07 \pm 1.09^{\mathrm{b}}$ & $3.32 \pm 0.13^{\mathrm{b}}$ & $0.01^{\mathrm{b}}$ \\
$3: 7$ & $91.43 \pm 3.51^{\mathrm{b}}$ & $89.45 \pm 3.55^{\mathrm{b}}$ & $2.83 \pm 0.18^{\mathrm{b}}$ & $0.22 \pm 0.02^{\mathrm{b}}$ \\
Doxorubicin & $73.10 \pm 4.90$ & $69.80 \pm 4.35$ & $11.07 \pm 0.07$ & $2.20 \pm 0.15^{\mathrm{b}}$ \\
\hline
\end{tabular}

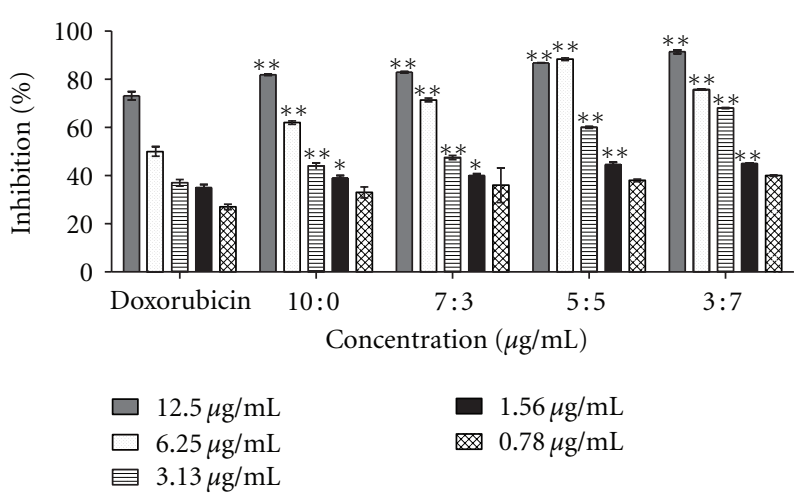

(a)

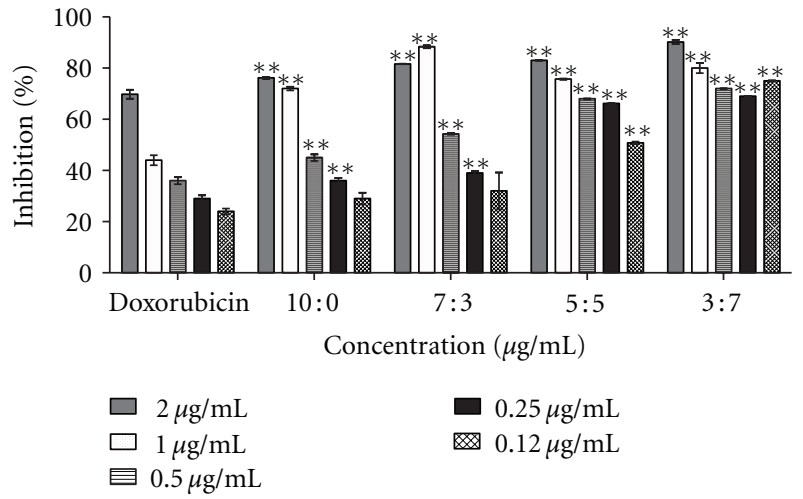

(b)

FIGURE 6: Cytotoxicity of doxorubicin loaded mixed micelles on MCF-7 and THP-1 cells. The \% inhibition of THP-1 cell growth (b) and MCF-7 (a) in response to specified concentrations of doxorubicin-loaded mixed micelles compared to free doxorubicin. Each data bar represents average $\pm \operatorname{SEM}(n=3),{ }^{*} P<0.05,{ }^{* *} P<0.01$.
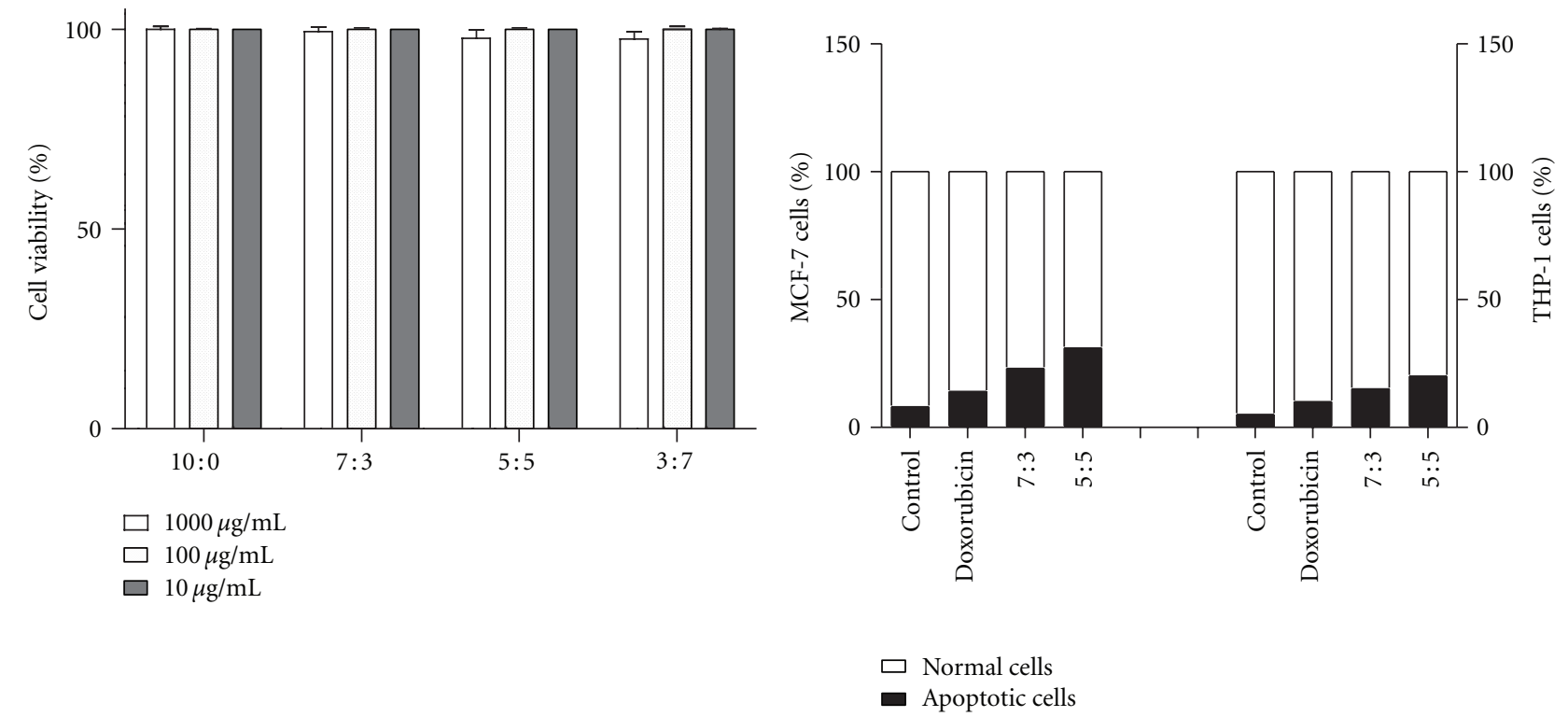

(a)

(b)

Figure 7: \% Cell viability and proapoptotic activity of mixed micelles. (a) The \% cell viability of V79 cells at 24 hours after incubation with increasing concentrations of blank micelles and (b) \% apoptotic and \% normal cells after treatment with drug-loaded micelles and free doxorubicin. 


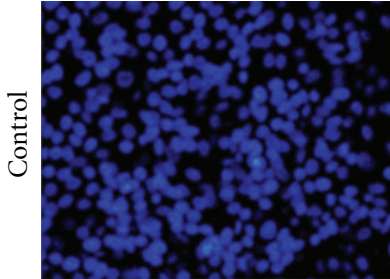

(a)

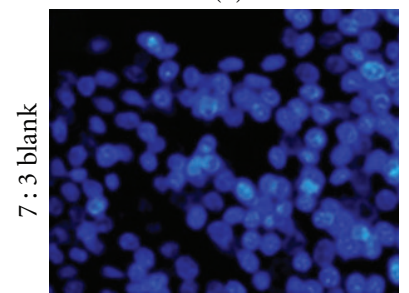

(e)

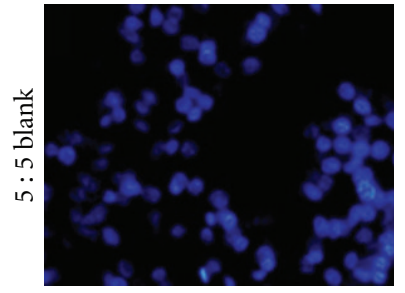

(i)

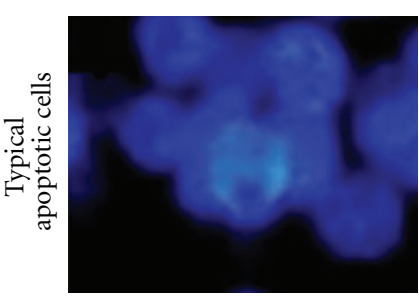

(m)

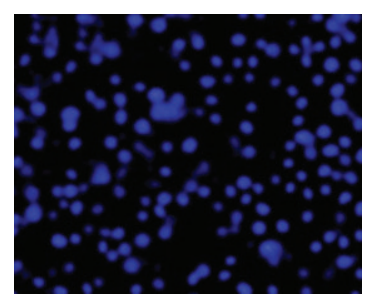

(b)

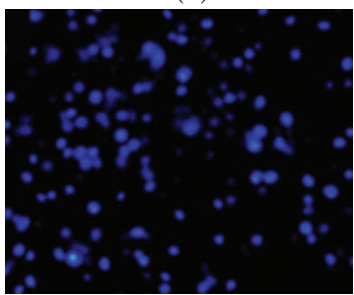

(f)

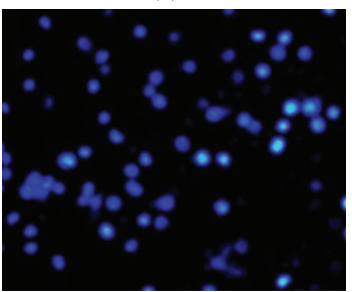

(j)

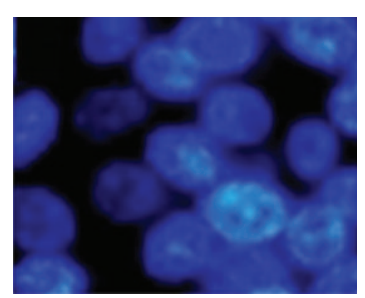

(n)

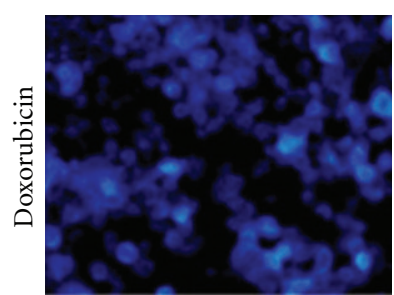

(c)

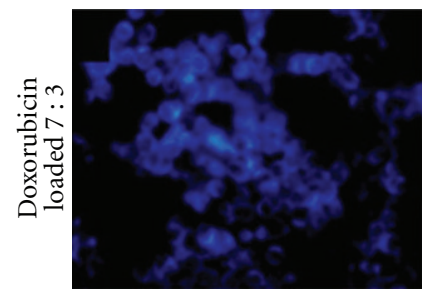

(g)

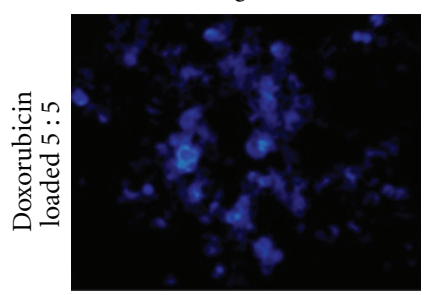

(k)

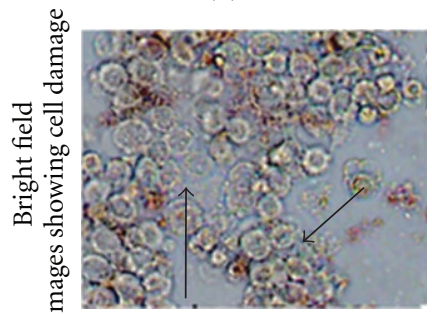

(o)

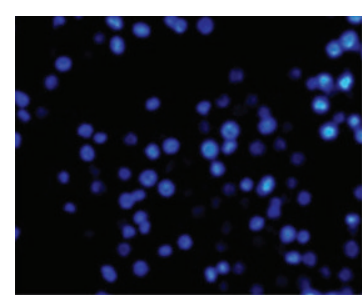

(d)

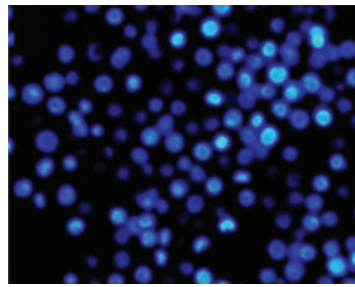

(h)

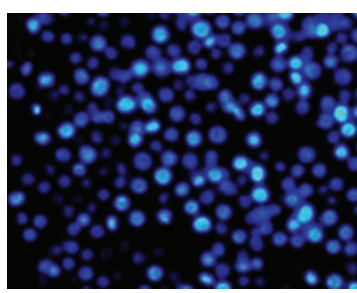

(1)

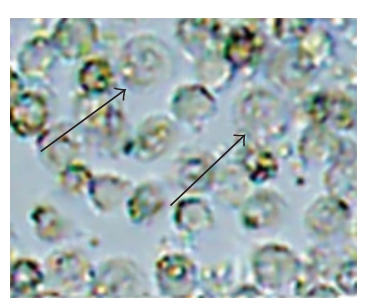

(p)

FIGURE 8: Fluorescence microscopy of cells treated with doxorubicin-loaded mixed micelles. Enhancement of apoptotic activity of doxorubicin in MCF-7 and THP-1 cells by Pluronic F127 and TPGS mixed micelles loaded with doxorubicin. Mixed micelles with various doxorubicin concentrations were incubated with both cell types for 48 hours before using Hoechst 33342 method for detection of apoptosis. At least 250 cells were counted for all the samples tested by Hoechst nuclear staining method. $(\mathrm{a}, \mathrm{b})$ they represent control cells. Cells treated with doxorubicin (c, d), 7:3 blank (e,f), doxorubicin loaded 7:3 (g,h), 5:5 blank (i,j), and doxorubicin loaded 5:5 (k,1). Horse shoe-shaped nucleus and karyorrhexis are shown $(\mathrm{m}, \mathrm{n}$ ) bright field image of MCF-7 and THP-1 cells showing cell damage caused by doxorubicin-loaded mixed micelles, apoptotic blebbing can be seen in THP-1 cells (o, p). Photographs were taken at identical exposure at 10x (a-1) and 400x $(\mathrm{m}-\mathrm{p})$ magnification powers.

than those for free doxorubicin. The lower percent inhibition and higher $\mathrm{IC}_{50}$ of doxorubicin compared to the doxorubicin-loaded mixed micelles could be attributed to the formation of aggregates, which hinder drug entry into cells. Moreover, doxorubicin could be eliminated from tumour sites by drug efflux pumps. In contrast, the increased cytotoxicity of the doxorubicin-loaded mixed micelles could be explained by the higher permeability and retention of micelles in tumour cells as well as the inhibition of drug efflux pumps or P-glycoproteins by Pluronic F127-TPGS mixed micelles. In addition, increased penetration of doxorubicin-loaded mixed micelles facilitates delivery of the drug to the site of action, which is located in the nucleus, and thus provides more time for doxorubicin to interact with its substrate. THP- 1 cells were more sensitive to the action of doxorubicin-loaded mixed micelles than MCF-7 cells as expected due to the lower $\mathrm{IC}_{50}$ of doxorubicin in these cells. Further, the cytotoxicity of doxorubicin increased from the $10: 0$ to the $3: 7$ combinations. The increased cytotoxicity in cancer cells could be associated with increased ROS production and enhanced apoptosis and partly to $\alpha$-tocopheryl succinate unimers of TPGS [27]. A dose-dependent relationship was observed in cell death for both free doxorubicin and entrapped doxorubicin. Cytotoxicity of doxorubicin is expected to increase further, in vivo, due to their EPR effects. These findings imply that selective uptake of mixed micelles by cancer cells could reduce the toxicity and adverse effects related to doxorubicin.

The proportions of normal and apoptotic THP- 1 and MCF-7 cells are provided in Figure 7(b). The apoptotic cell 
population significantly increased following the treatments with free doxorubicin and doxorubicin-loaded mixed micelles. However, the doxorubicin-loaded mixed micelles $(7: 3=$ $23 \%, 5: 5=31 \%)$ induced greater apoptotic activity than free doxorubicin (14\%) in MCF-7 cells. Similarly, more apoptotic THP-1 cells were produced by the doxorubicin-loaded mixed micelles $(7: 3=16 \%, 5: 5=19 \%)$ than free doxorubicin (10\%).

Both Pluronic F127 and TPGS may account for this increase in apoptotic activity, because these polymers have proapoptotic effects. The increase in the TPGS concentration intensified the apoptotic activity particularly in MCF-7 cells. The results reveal that a higher proportion of apoptotic cells was produced by the doxorubicin-loaded mixed micelles, suggesting that the micelles effectively delivered doxorubicin to the target cells. Control and treated cells visualized under a fluorescence microscope after staining with Hoechst 33342 for specified intervals are shown in Figure 8. The presence of condensed chromatin, damaged nuclei and cell membranes (bright-field image), pyknotic nuclei, and karyorrhexis are signs of apoptosis.

\section{Conclusions}

Doxorubicin-loaded mixed micelles of Pluronic F127 and TPGS were successfully prepared and characterized. To the best of our knowledge, this work is the first attempt to develop Pluronic F127-TPGS mixed micelles for targeted doxorubicin delivery. The results suggest that Pluronic F127TPGS mixed micelles have great potential as nanocarriers for targeted delivery of poorly soluble, hydrophobic anticancer drugs. However, studies of their pharmacokinetics and pharmacodynamics in animal models are warranted.

\section{Conflict of Interests}

The authors declare no conflict of interests with regard to the work.

\section{Acknowledgments}

This work was supported by Research Grants (GUP-SK07-23-045) from the Universiti Kebangsaan Malaysia and Science Fund (02-01-02-SF0738) from Ministry of Science, Technology and Innovation (MOSTI), Malaysia. The funding sources had no role in any part of the study.

\section{References}

[1] A. Laengler, C. Spix, G. Seifert, S. Gottschling, N. Graf, and P. Kaatsch, "Complementary and alternative treatment methods in children with cancer: a population-based retrospective survey on the prevalence of use in Germany," European Journal of Cancer, vol. 44, no. 15, pp. 2233-2240, 2008.

[2] I. Brigger, C. Dubernet, and P. Couvreur, "Nanoparticles in cancer therapy and diagnosis," Advanced Drug Delivery Reviews, vol. 54, no. 5, pp. 631-651, 2002.

[3] S. S. Feng, L. Zhao, Z. Zhang et al., "Chemotherapeutic engineering: vitamin E TPGS-emulsified nanoparticles of biodegradable polymers realized sustainable paclitaxel chemotherapy for $168 \mathrm{~h}$ in vivo," Chemical Engineering Science, vol. 62, no. 23, pp. 6641-6648, 2007.

[4] A. J. Primeau, A. Rendon, D. Hedley, L. Lilge, and I. F. Tannock, "The distribution of the anticancer drug doxorubicin in relation to blood vessels in solid tumors," Clinical Cancer Research, vol. 11, no. 24, pp. 8782-8788, 2005.

[5] A. Hatefi and B. Amsden, "Camptothecin delivery methods," Pharmaceutical Research, vol. 19, no. 10, pp. 1389-1399, 2002.

[6] J. Williams, R. Lansdown, R. Sweitzer et al., "Nanoparticle drug delivery system for intravenous delivery of topoisomerase inhibitors," Journal of Controlled Release, vol. 91, no. 1-2, pp. 167-172, 2003.

[7] N. R. Patel, A. Rathi, D. Mongayt, and V. P. Torchilin, "Reversal of multidrug resistance by co-delivery of tariquidar (XR9576) and paclitaxel using long-circulating liposomes," International Journal of Pharmaceutics, vol. 416, no. 1, pp. 296-299, 2011.

[8] X. Li, L. Ding, Y. Xu, Y. Wang, and Q. Ping, "Targeted delivery of doxorubicin using stealth liposomes modified with transferrin," International Journal of Pharmaceutics, vol. 373, no. 12, pp. 116-123, 2009.

[9] K. Letchford and H. Burt, "A review of the formation and classification of amphiphilic block copolymer nanoparticulate structures: micelles, nanospheres, nanocapsules and polymersomes," European Journal of Pharmaceutics and Biopharmaceutics, vol. 65, no. 3, pp. 259-269, 2007.

[10] Y. Hu, Y. Ding, D. Ding et al., "Hollow chitosan/poly(acrylic acid) nanospheres as drug carriers," Biomacromolecules, vol. 8, no. 4, pp. 1069-1076, 2007.

[11] R. Tong and J. Cheng, "Anticancer polymeric nanomedicines," Polymer Reviews, vol. 47, no. 3, pp. 345-381, 2007.

[12] V. P. Torchilin, "Structure and design of polymeric surfactantbased drug delivery systems," Journal of Controlled Release, vol. 73, no. 2-3, pp. 137-172, 2001.

[13] V. P. Torchilin, "Micellar nanocarriers: pharmaceutical perspectives," Pharmaceutical Research, vol. 24, no. 1, pp. 1-16, 2007.

[14] K. Kataoka, A. Harada, and Y. Nagasaki, "Block copolymer micelles for drug delivery: design, characterization and biological significance," Advanced Drug Delivery Reviews, vol. 47, no. 1, pp. 113-131, 2001.

[15] L. Mu, T. A. Elbayoumi, and V. P. Torchilin, "Mixed micelles made of poly(ethylene glycol)-phosphatidylethanolamine conjugate and D- $\alpha$-tocopheryl polyethylene glycol 1000 succinate as pharmaceutical nanocarriers for camptothecin," International Journal of Pharmaceutics, vol. 306, no. 1-2, pp. 142$149,2005$.

[16] Y. Matsumura, T. Hamaguchi, T. Ura et al., "Phase I clinical trial and pharmacokinetic evaluation of NK911, a micelleencapsulated doxorubicin," British Journal of Cancer, vol. 91, no. 10, pp. 1775-1781, 2004.

[17] R. Plummer, R. H. Wilson, H. Calvert et al., "A phase I clinical study of cisplatin-incorporated polymeric micelles (NC-6004) in patients with solid tumours," British Journal of Cancer, vol. 104, no. 4, pp. 593-598, 2011.

[18] T. Hamaguchi, K. Kato, H. Yasui et al., "A phase I and pharmacokinetic study of NK105, a paclitaxel-incorporating micellar nanoparticle formulation," British Journal of Cancer, vol. 97, no. 2, pp. 170-176, 2007.

[19] W. Zhang, Y. Shi, Y. Chen et al., "Enhanced antitumor efficacy by paclitaxel-loaded pluronic P123/F127 mixed micelles against non-small cell lung cancer based on passive tumor targeting and modulation of drug resistance," European Journal 
of Pharmaceutics and Biopharmaceutics, vol. 75, no. 3, pp. 341353, 2010.

[20] V. Alakhov and A. Kabanov, "Block copolymer-based formulations of doxorubicin efective against drug resistant tumours," in Biomedical Polymers and Polymer Therapeutics, E. Chiellini, J. Sunamoto, C. Migliaresi, R. M. Ottenbrite, and D. Cohn, Eds., pp. 121-137, Kluwer Academic, New York, NY, USA, 2002.

[21] A. V. Kabanov, E. V. Batrakova, and V. Y. Alakhov, "Pluronic block copolymers as novel polymer therapeutics for drug and gene delivery," Journal of Controlled Release, vol. 82, no. 2-3, pp. 189-212, 2002.

[22] V. Y. Alakhov, E. Y. Moskaleva, E. V. Batrakova, and A. V. Kabanov, "Hypersensitization of multidrug resistant human ovarian carcinoma cells by pluronic P85 block copolymer," Bioconjugate Chemistry, vol. 7, no. 2, pp. 209-216, 1996.

[23] E. V. Batrakova, S. Li, A. M. Brynskikh et al., "Effects of pluronic and doxorubicin on drug uptake, cellular metabolism, apoptosis and tumor inhibition in animal models of MDR cancers," Journal of Controlled Release, vol. 143, no. 3, pp. 290-301, 2010.

[24] E. V. Batrakova, S. Li, W. F. Elmquist, D. W. Miller, V. Y. Alakhov, and A. V. Kabanov, "Mechanism of sensitization of MDR cancer cells by pluronic block copolymers: selective energy depletion," British Journal of Cancer, vol. 85, no. 12, pp. 1987-1997, 2001.

[25] L. B. Li and Y. B. Tan, "Preparation and properties of mixed micelles made of pluronic polymer and PEG-PE," Journal of Colloid and Interface Science, vol. 317, no. 1, pp. 326-331, 2008.

[26] Y. Gao, L. B. Li, and G. Zhai, "Preparation and characterization of pluronic/TPGS mixed micelles for solubilization of camptothecin," Colloids and Surfaces B, vol. 64, no. 2, pp. 194-199, 2008.

[27] H. J. Youk, E. Lee, M. K. Choi et al., "Enhanced anticancer efficacy of $\alpha$-tocopheryl succinate by conjugation with polyethylene glycol," Journal of Controlled Release, vol. 107, no. 1, pp. 43-52, 2005.

[28] C. H. Wang, C. H. Wang, and G. H. Hsiue, "Polymeric micelles with a $\mathrm{pH}$-responsive structure as intracellular drug carriers," Journal of Controlled Release, vol. 108, no. 1, pp. 140-149, 2005.

[29] H. Tan, Y. Zhang, M. Wang et al., "Silica-shell cross-linked micelles encapsulating fluorescent conjugated polymers for targeted cellular imaging," Biomaterials, vol. 33, no. 1, pp. 237246, 2012.

[30] Z. G. Gao, H. D. Fain, and N. Rapoport, "Controlled and targeted tumor chemotherapy by micellar-encapsulated drug and ultrasound," Journal of Controlled Release, vol. 102, no. 1, pp. 203-222, 2005.

[31] V. P. Torchilin, "PEG-based micelles as carriers of contrast agents for different imaging modalities," Advanced Drug Delivery Reviews, vol. 54, no. 2, pp. 235-252, 2002.

[32] H. Hu, J. Yu, Y. Li, J. Zhao, and H. Dong, "Engineering of a novel pluronic F127/graphene nanohybrid for $\mathrm{pH}$ responsive drug delivery," Journal of Biomedical Materials Research Part A, vol. 100, no. 1, pp. 141-148, 2012.

[33] W. Zhang, Y. Shi, Y. Chen, J. Hao, X. Sha, and X. Fang, "The potential of pluronic polymeric micelles encapsulated with paclitaxel for the treatment of melanoma using subcutaneous and pulmonary metastatic mice models," Biomaterials, vol. 32, no. 25, pp. 5934-5944, 2011.

[34] G. Gaucher, M. H. Dufresne, V. P. Sant, N. Kang, D. Maysinger, and J. C. Leroux, "Block copolymer micelles: preparation, characterization and application in drug delivery," Journal of Controlled Release, vol. 109, no. 1-3, pp. 169-188, 2005.
[35] P. Chandrasekharan, D. Maity, C. X. Yong, K. H. Chuang, J. Ding, and S. S. Feng, "Vitamin E (D-alpha-tocopheryl-copoly(ethylene glycol) 1000 succinate) micelles-superparamagnetic iron oxide nanoparticles for enhanced thermotherapy and MRI," Biomaterials, vol. 32, no. 24, pp. 5663-5672, 2011. 

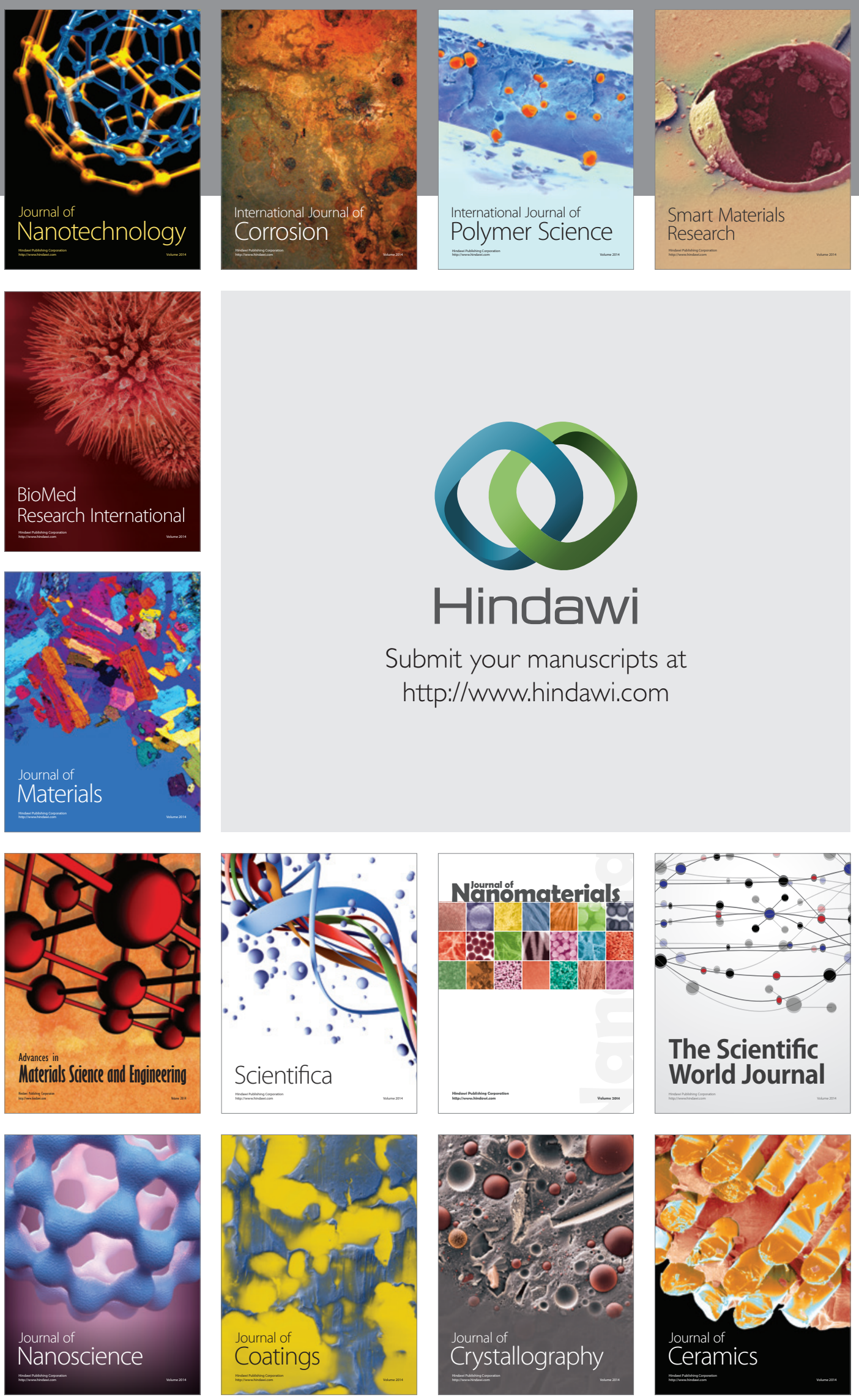

The Scientific World Journal

Submit your manuscripts at

http://www.hindawi.com

\section{World Journal}

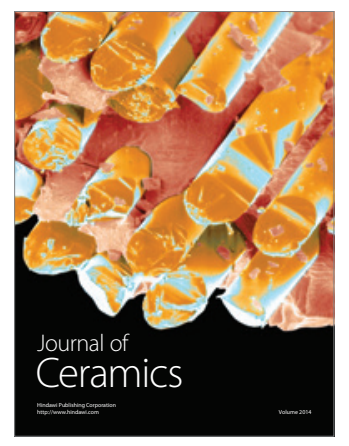

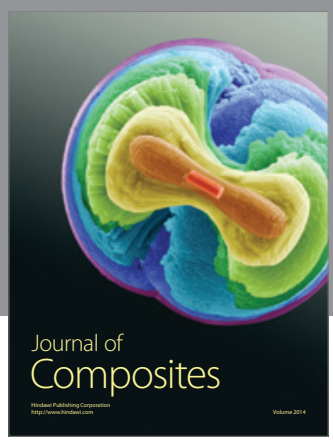
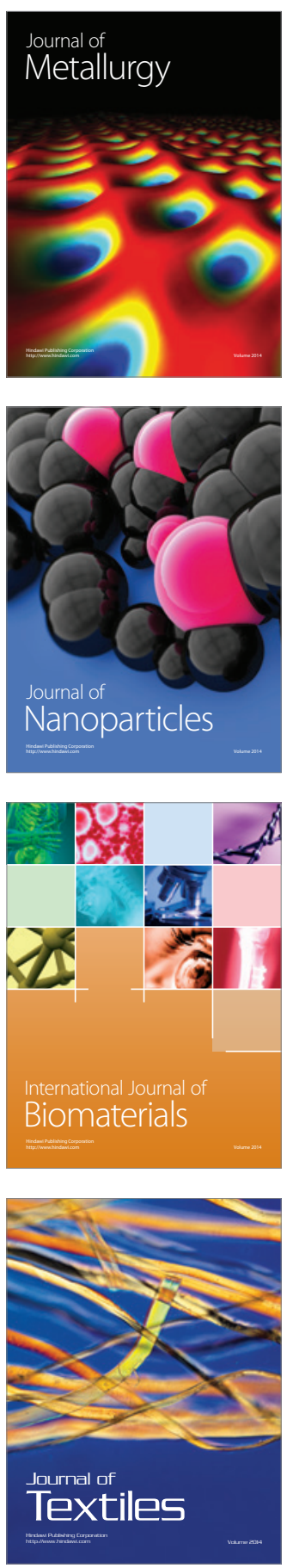